\title{
Technical Innovation of Electrostimulation Biofeedback Combined with Vaginal Dumbbell in the Treatment of Postpartum Pelvic Floor Dysfunction
}

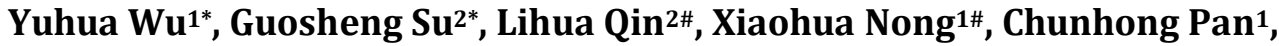 \\ Han Wei ${ }^{1}$, Yulan Wei ${ }^{1}$, Fangxiu Liu ${ }^{1}$
}

${ }^{1}$ Departmnt of Obstetric, Southwest Hospital Affiliated to Youjiang Medical College for Nationalities, Baise People's Hospital, Baise, China

${ }^{2}$ Department of Osteoarthritis and Clinical Laboratory, Guigang Red Cross Hospital, Guigang Hospital of Integrated Traditional Chinese and Western Medicine, Guigang, China

Email: 158191524@qq.com, 563449581@qq.com, "787209349@qq.com, "349679983@qq.com, 13877682019@163.com, 8858381@qq.com,273388177@qq.com,2281626447@qq.com

How to cite this paper: Wu, Y.H., Su, G.S., Qin, L.H., Nong, X.H., Pan, C.H., Wei, H., Wei, Y.L. and Liu, F.X. (2020) Technical Innovation of Electrostimulation Biofeedback Combined with Vaginal Dumbbell in the Treatment of Postpartum Pelvic Floor Dysfunction. Open Journal of Obstetrics and Gynecology, 10, 463-477.

https://doi.org/10.4236/ojog.2020.1040042

Received: March 5, 2020

Accepted: April 5, 2020

Published: April 8, 2020

Copyright $(2020$ by author(s) and Scientific Research Publishing Inc. This work is licensed under the Creative Commons Attribution International License (CC BY 4.0).

http://creativecommons.org/licenses/by/4.0/ (c) (i) Open Access

\begin{abstract}
Objective: To investigate the application value of electrostimulation biofeedback therapy in combination with vaginal dumbbell therapy to postpartum pelvic floor dysfunction. Methods: Retrospective analysis of 200 cases of postpartum pelvic floor dysfunction patients discharged from the hospital from January 2016 to March 2019 as study subjects who were excluded other underlying diseases and were randomly divided into two groups of 100 cases per group, using electrostimulation biofeedback therapy combined vaginal dumbbell therapy as a treatment group. The treatment of electrostimulation biofeedback therapy in combination with kegel was treated as a control group. Then the curative effects of the two groups were compared and statistically analyzed. Results: There was no significant difference in EMG value of postpartum pelvic floor treatment, type I muscle strength, type II muscle strength, muscle type I fatigue, type II fatigue and POP-Q detection results between the two groups before treatment, $\mathrm{p}>0.05$. There were significant differences in type I muscle strength, type II muscle strength and muscle type I fatigue between the pelvic floor muscles and the muscles at the end of the treatment day, the sixth month and one year after treatment, $\mathrm{p}<0.05$. There was no statistically significant difference at the end of muscle type II fatigue
\end{abstract}

${ }^{*}$ Co-first authors, ${ }^{\#}$ Co-corresponding author. 
treatment day, $p>0.05$; while after the treatment of six months and one year, the difference was statistically significant, $p<0.05$. There was no statistically significant difference between the day after POP-Q detection treatment, the six months after treatment, and the year after treatment, $p>0.05$. In addition, the treatment group and the control group were compared before and after treatment, the difference of myoelectric potential value, pelvic floor muscle type I muscle strength, type II muscle strength, muscle type I fatigue degree, type II fatigue degree and POP-Q test result were significant, and the changes in the indicators before and after treatment in the treatment group were significantly higher than the control group. Comparison of urinary incontinence between the two groups before and after treatment, the difference between pre-treatment and the end of treatment day was not statistically significant, $p>0.05$; there was significant difference between half a year and one year after treatment $(\mathrm{p}<0.05)$. After the comparison of the number of cases in the two groups who were not satisfied with their sexual life and did not dare to have sex before treatment, the difference was not statistically significant ( $p>$ 0.05 , respectively). Comparing the satisfaction with sexual life after the time of treatment day, half a year and one year after the end of treatment, the difference was statistically significant $(p<0.05)$. Conclusion: Electrical stimulation biofeedback therapy combined with vaginal dumbbell therapy has a good effect in the treatment of postpartum pelvic floor dysfunction, and it is worthy of popularization and application.

\section{Keywords}

Electrical Stimulation, Biofeedback Therapy, Dumbbell Therapy, Postpartum, Pelvic Floor, Dysfunction

\section{Introduction}

Postpartum pelvic floor dysfunction is a common disease that affects the reproductive health of modern women, which makes many women bear great psychological pressure. Postpartum pelvic floor functional rehabilitation is the life goal pursued by most women [1] [2] [3] [4] [5]. In the past, discharged parturients were asked to return to hospital 42 days after delivery for pelvic floor screening. Patients with pelvic floor dysfunction were treated with electrical stimulation biofeedback therapy combined with kegel [6] [7] [8] [9] [10]. In order to find a better treatment, this study explored the use of electrical stimulation biofeedback therapy combined with vaginal dumbbell to treat patients with postpartum pelvic floor dysfunction in order to achieve the best results. The results of the study are reported as follows.

\section{Materials and Methods}

\subsection{Research Object}

200 patients with postpartum pelvic floor dysfunction who were discharged 
from our hospital from January 2016 to March 2019 were selected as subjects. The all subjects had the following characteristics: the age was 18 - 49 years, the average age was $(26.5 \pm 2.5)$ years. All the patients were about 6 weeks postpartum, all of them had excluded other basic diseases, and the best period of treatment for postpartum pelvic floor dysfunction was within 2 months after delivery. Among them, 100 patients with postpartum pelvic floor dysfunction were treated with electrical stimulation biofeedback therapy combined with vaginal dumbbell as the treatment group, and the other 100 patients with postpartum pelvic floor dysfunction were treated with electrical stimulation biofeedback therapy combined with kegel as the control group. The disease status, age, weight, pregnancy time, mode of delivery, and postpartum treatment time of the selected cases were basically the same and there was no statistically significant difference in the basic conditions between the two groups. The subjects listed in this study were approved by the Ethics Committee of the Institute and implemented with the consent of the patients.

\subsection{Treatment Programs}

Firstly, the PHENIX U4 neuromuscular stimulation therapeutic instrument was programmed, and then the equipment was maintained and calibrated for use. The pelvic floor muscle potential could be detected by the calibrated equipment, and different training modes could be worked out on the basis of the maximum and minimum values of the muscle voltage. The treatment could be divided into three stages. The first stage of treatment was called "Electric Stimulation": the electrical stimulation was given at a frequency of $50 \mathrm{~Hz}$ and the pulse width was $250 \mu \mathrm{s}$; the effect was to awaken the patient's proprioception; the electrical stimulation could adjust the patient's blood circulation and muscle sensitivity and number of muscles; treatment time was 25 minutes. This stage was used for the first, second and tenth treatment. The second stage of treatment was named "Conditional Reflex": Electrical stimulation with a frequency of $32 \mathrm{~Hz}$ and a pulse width of $740 \mu$ s and a biofeedback map of type I muscle fibers were used to train the patient to learn the contraction of type I muscle fibers and to distinguish the contractions of the vaginal and abdomen. The treatment time was 20 minutes, and this stage was used for the third and fourth time. The third stage of treatment was named "Overall Training":

Electrical stimulation with a frequency of $80 \mathrm{~Hz}$, a pulse width of $320 \mu \mathrm{s}$, and a biofeedback of type I and II muscle fibers were used to enhance the muscle strength of type I and II muscle fibers in patients. The treatment time was 20 minutes, and this stage was used for the fifth to ninth time of treatment. The control group was treated with electrical stimulation biofeedback therapy according to the routine program in the hospital, twice a week, 10 times as a course of treatment and one course of treatment. From the beginning of the treatment, the patients were guided by the pelvic floor rehabilitation teacher to carry out kegel training at home, and trained 150 up to 200 times daily which was incorporated into daily life training [11] [12] [13] [14] [15]. On the basis of 
the control group, the treatment group was guided by the pelvic floor rehabilitation teacher to carry out vaginal dumbbell training at home; Under the exclusion of vaginitis and vaginal bleeding, the patients were trained once a day or every other day for 10 to 20 minutes at a time until to check the pelvic floor muscle strength is normal, and then change to practice once or twice a week, which was incorporated into daily life training. In both groups, the pelvic floor muscle strength was examined as the efficacy evaluation standard on the day after the end of treatment, the sixth month, and one year. Effective judgment: 1) Examination of electrophysiological indexes of pelvic floor: a) The muscle potential value is above $15 \mu \mathrm{V}$; b) The pelvic floor muscles of type I and type II muscle fibers strength reached grade III and above; c) Type I and II muscle fiber fatigue is $-1 \%$ - 0\%. 2) Quantitative assessment of pelvic organ prolapse quantitative (POP-Q) indexing method: The distance between the cervix and the hymen was $>4 \mathrm{~cm}$. 3) Specific classification and examination of urinary incontinence: Urinary incontinence grade decreased by more than 2 degrees. 4) Sexual life satisfaction questionnaires were distributed to patients, and the quality of sexual life was evaluated by questionnaire results, which was effective from unsatisfactory quality of sexual life to satisfaction.

\subsection{Statistical Analysis}

Statistical analysis was performed using SPSS19.0 statistical software. The measurement data were analyzed by t-test of two independent samples. The count data were analyzed by $\chi^{2}$ test or Fisher exact probability method, $\mathrm{p}<0.05$ was considered statistically significant.

\section{Results}

\subsection{Comparison of Pelvic Floor Function between the Two Groups before and after Treatment}

There were no statistically significant differences in postpartum pelvic floor treatment of myoelectric potential, pelvic floor muscle type I muscle strength, type II muscle strength, muscle type I fatigue, type II fatigue and POP-Q test results between the two groups before treatment $(p>0.05)$. On the day after treatment, the sixth month and one year, the difference of type I muscle strength, type II muscle strength and muscle type I fatigue of pelvic floor muscles was statistically significant, $p<0.05$. However, there was no significant difference in the end of type II fatigue treatment, $p>0.05$; the difference was statistically significant at 6 months and 1 year after treatment, $\mathrm{p}<0.05$. There was no significant difference in the day, sixth month and one year after the end of POP-Q treatment, $p>0.05$. See Tables 1-6 below for details.

\subsection{Comparison of Pelvic Floor Function before and after Treatment in Treatment Group}

In the treatment group, the myoelectric potential value of pelvic floor function, 
muscle type I muscle strength, muscle type II muscle strength, muscle type I fatigue, muscle type II fatigue, POP-Q test before and after treatment, before and half a year after treatment, before and one year after treatment were statistically significant $(\mathrm{p}<0.001)$; There were significant differences in EMG potential, muscle type II muscle strength, muscle type I fatigue and muscle type II fatigue between the two groups on the end of the same treatment day and half a year after treatment $(p<0.05)$; There was no significant difference between the same day after the muscle type I muscle strength treatment and the half year after treatment, $\mathrm{p}>0.05$; There were significant differences in EMG potential, muscle type I muscle strength, muscle type II muscle strength, muscle type I fatigue, muscle type II fatigue and other indicators between the end of the same treatment day and one year after treatment $(\mathrm{p}<0.05)$; There were no statistically significant differences in muscle potential values, muscle type I muscle strength, muscle type II muscle strength, muscle type I fatigue, and muscle type II fatigue on the time of half a year and one year after the treatment, $(p>0.05)$; There was no significant difference in POP-Q detection between the day after treatment and half a year after treatment, the day after treatment and one year after treatment, and the difference between half a year after treatment and one year after treatment $(p>0.05)$. See Table 7 below for details.

Table 1. Comparison of muscle potentials in postpartum pelvic floor therapy between the two groups.

\begin{tabular}{cccccc}
\hline Group & $\begin{array}{c}\text { No. } \\
\text { of cases }\end{array}$ & $\begin{array}{c}\text { EMG value } \\
\text { before } \\
\text { treatment }\end{array}$ & $\begin{array}{c}\text { EMG value } \\
\text { after the same } \\
\text { treatment day }\end{array}$ & $\begin{array}{c}\text { EMG value half } \\
\text { a year after } \\
\text { treatment }\end{array}$ & $\begin{array}{c}\text { EMG value } \\
\text { one year after } \\
\text { treatment }\end{array}$ \\
\hline $\begin{array}{c}\text { Treatment } \\
\text { Group }\end{array}$ & 100 & $5.85 \pm 2.21$ & $15.64 \pm 3.67$ & $16.66 \pm 2.58$ & $17.21 \pm 2.28$ \\
$\begin{array}{c}\text { Control } \\
\text { Group }\end{array}$ & 100 & $5.73 \pm 1.89$ & $14.60 \pm 3.65$ & $15.41 \pm 3.24$ & $14.50 \pm 2.99$ \\
T Value & - & 0.4127 & 2.0093 & 3.0181 & 7.2072 \\
p Value & - & 0.3402 & 0.0229 & 0.0014 & 0.0000 \\
\hline
\end{tabular}

Table 2. Comparison of Type I muscle strength of pelvic floor muscles between the two groups.

\begin{tabular}{cccccc}
\hline Group & $\begin{array}{c}\text { No. } \\
\text { of cases } \\
\text { type I muscle } \\
\text { strength before } \\
\text { treatment }\end{array}$ & $\begin{array}{c}\text { Pelvic floor muscle } \\
\text { type I muscle } \\
\text { strength after the } \\
\text { same treatment day }\end{array}$ & $\begin{array}{c}\text { Pelvic floor muscle Pelvic floor muscle } \\
\text { type I muscle } \\
\text { strength half a year } \\
\text { after treatment }\end{array}$ & $\begin{array}{c}\text { type I muscle } \\
\text { strength one year } \\
\text { after treatment }\end{array}$ \\
\hline $\begin{array}{c}\text { Treatment } \\
\text { Group }\end{array}$ & 100 & $1.63 \pm 0.56$ & $3.08 \pm 0.79$ & $3.22 \pm 0.72$ & $3.34 \pm 0.70$ \\
$\begin{array}{c}\text { Control } \\
\text { Group }\end{array}$ & 100 & $1.61 \pm 0.62$ & $2.76 \pm 0.81$ & $2.9 \pm 0.69$ & $2.77 \pm 0.58$ \\
T Value & - & 0.2394 & 2.8282 & 3.2088 & 6.2702 \\
p Value & - & 0.4055 & 0.0026 & 0.0008 & 0.0000
\end{tabular}


Table 3. Comparison of Type II muscle strength of pelvic floor muscles between the two groups.

\begin{tabular}{cccccc}
\hline Group & $\begin{array}{c}\text { No. } \\
\text { of cases }\end{array}$ & $\begin{array}{c}\text { Pelvic floor } \\
\text { muscle type II } \\
\text { muscle strength } \\
\text { before treatment }\end{array}$ & $\begin{array}{c}\text { Pelvic floor } \\
\text { muscle type II } \\
\text { muscle strength } \\
\text { after the same } \\
\text { treatment day }\end{array}$ & $\begin{array}{c}\text { Pelvic floor muscle } \\
\text { type II muscle } \\
\text { strength half a year } \\
\text { after treatment }\end{array}$ & $\begin{array}{c}\text { Pelvic floor muscle } \\
\text { type II muscle } \\
\text { strength one year } \\
\text { after treatment }\end{array}$ \\
\hline $\begin{array}{c}\text { Treatment } \\
\text { Group }\end{array}$ & 100 & $1.62 \pm 0.56$ & $3.15 \pm 0.86$ & $3.47 \pm 0.82$ & $3.57 \pm 0.81$ \\
$\begin{array}{c}\text { Control } \\
\text { Group }\end{array}$ & 100 & $1.61 \pm 0.60$ & $2.89 \pm 0.76$ & $3.03 \pm 0.76$ & $2.88 \pm 0.59$ \\
T Value & - & 0.1218 & 2.2654 & 3.9355 & 6.8856 \\
p Value & - & 0.4516 & 0.0123 & 0.0001 & 0.0000 \\
\hline
\end{tabular}

Table 4. Comparison of Class I fatigue of two groups of pelvic floor muscles.

\begin{tabular}{cccccc}
\hline Group & $\begin{array}{c}\text { No. } \\
\text { of cases I fatigue of } \\
\text { pelvic floor } \\
\text { muscles before } \\
\text { treatment }\end{array}$ & $\begin{array}{c}\text { Type I fatigue of } \\
\text { pelvic floor muscles } \\
\text { after the same } \\
\text { treatment day }\end{array}$ & $\begin{array}{c}\text { Type I fatigue of } \\
\text { half a year after } \\
\text { treatment }\end{array}$ & $\begin{array}{c}\text { Type I fatigue of } \\
\text { one year after } \\
\text { treatment }\end{array}$ \\
\hline $\begin{array}{c}\text { Treatment } \\
\text { Group }\end{array}$ & 100 & $-2.65 \pm 0.90$ & $-1.01 \pm 0.67$ & $-0.71 \pm 0.59$ & $-0.66 \pm 0.59$ \\
$\begin{array}{c}\text { Control } \\
\text { Group }\end{array}$ & 100 & $-2.66 \pm 0.91$ & $-1.28 \pm 0.85$ & $-1.05 \pm 0.76$ & $-1.20 \pm 0.74$ \\
T Value & - & 0.0781 & 2.4947 & 3.5338 & 5.7057 \\
p Value & - & 0.4689 & 0.0067 & 0.0003 & 0.0000 \\
\hline
\end{tabular}

Table 5. Comparison of Class II fatigue of two groups of pelvic floor muscles.

\begin{tabular}{cccccc}
\hline Group & $\begin{array}{c}\text { Type II fatigue } \\
\text { of cases } \\
\text { of pelvic floor } \\
\text { muscles before } \\
\text { treatment }\end{array}$ & $\begin{array}{c}\text { Type II fatigue of } \\
\text { pelvic floor muscles } \\
\text { after the same } \\
\text { treatment day }\end{array}$ & $\begin{array}{c}\text { Type II fatigue of } \\
\text { pelvic floor muscles } \\
\text { half a year after } \\
\text { treatment }\end{array}$ & $\begin{array}{c}\text { Type II fatigue of } \\
\text { pelvic floor muscles } \\
\text { one year after } \\
\text { treatment }\end{array}$ \\
\hline $\begin{array}{c}\text { Treatment } \\
\text { Group }\end{array}$ & 100 & $-2.36 \pm 0.81$ & $-0.95 \pm 0.73$ & $-0.59 \pm 0.62$ & $-0.55 \pm 0.63$ \\
$\begin{array}{c}\text { Control } \\
\text { Group }\end{array}$ & 100 & $-2.4 \pm 0.99$ & $-1.03 \pm 0.85$ & $-0.79 \pm 0.74$ & $-0.89 \pm 0.75$ \\
T Value & - & 0.3127 & 0.714 & 2.0717 & 3.4712 \\
p Value & - & 0.3774 & 0.238 & 0.0198 & 0.0003 \\
\hline
\end{tabular}

Table 6. Comparison of POP-Q tests between two groups.

\begin{tabular}{cccccc}
\hline Group & $\begin{array}{c}\text { No. } \\
\text { of cases }\end{array}$ & $\begin{array}{c}\text { POP-Q tests } \\
\text { before treatment }\end{array}$ & $\begin{array}{c}\text { POP-Q tests after } \\
\text { the same treatment } \\
\text { day }\end{array}$ & $\begin{array}{c}\text { POP-Q tests half } \\
\text { a year after } \\
\text { treatment }\end{array}$ & $\begin{array}{c}\text { POP-Q tests one } \\
\text { year after } \\
\text { treatment }\end{array}$ \\
\hline $\begin{array}{c}\text { Treatment } \\
\text { Group }\end{array}$ & 100 & $-4.63 \pm 0.61$ & $-4.98 \pm 0.31$ & $-5.01 \pm 0.24$ & $-5.01 \pm 0.24$ \\
$\begin{array}{c}\text { Control } \\
\text { Group }\end{array}$ & 100 & $-4.58 \pm 0.79$ & $-5.00 \pm 0.36$ & $-5.01 \pm 0.35$ & $-5.01 \pm 0.35$ \\
$\begin{array}{c}\text { T Value } \\
\text { p Value }\end{array}$ & - & 0.5010 & 0.4210 & 0.0000 & 0.0000 \\
\hline
\end{tabular}


Table 7. Comparison of pelvic floor function before and after treatment in treatment group.

\begin{tabular}{|c|c|c|c|c|c|c|}
\hline Project & EMG Value & $\begin{array}{l}\text { Muscle Type I } \\
\text { Muscle Strength }\end{array}$ & $\begin{array}{l}\text { Muscle Type II } \\
\text { Muscle Strength }\end{array}$ & $\begin{array}{l}\text { Muscle Type I } \\
\text { Fatigue }\end{array}$ & $\begin{array}{c}\text { Muscle Type II } \\
\text { Fatigue }\end{array}$ & POP-Q Test \\
\hline Before Treatment & $5.85 \pm 2.21$ & $1.63 \pm 0.56$ & $1.62 \pm 0.56$ & $-2.65 \pm 0.90$ & $-2.36 \pm 0.81$ & $-4.63 \pm 0.61$ \\
\hline On the Day of Treatment & $15.64 \pm 3.67$ & $3.08 \pm 0.79$ & $3.15 \pm 0.86$ & $-1.01 \pm 0.67$ & $-0.95 \pm 0.73$ & $-4.98 \pm 0.31$ \\
\hline Half a Year After Treatment & $16.66 \pm 2.58$ & $3.22 \pm 0.72$ & $3.47 \pm 0.82$ & $-0.71 \pm 0.59$ & $-0.59 \pm 0.62$ & $-5.01 \pm 0.24$ \\
\hline One Year After Treatment & $17.21 \pm 2.28$ & $3.34 \pm 0.70$ & $3.57 \pm 0.81$ & $-0.66 \pm 0.59$ & $-0.55 \pm 0.63$ & $-5.01 \pm 0.24$ \\
\hline $\begin{array}{l}\text { Comparison of } \mathrm{T} \text { value/p value } \\
\text { before treatment and on the day } \\
\text { of treatment }\end{array}$ & $22.8523 / 0.0000$ & $14.9739 / 0.0000$ & $14.9086 / 0.0000$ & $14.6167 / 0.0000$ & $12.9309 / 0.0000$ & $5.1151 / 0.0000$ \\
\hline $\begin{array}{l}\text { Comparison of } \mathrm{T} \text { value/p value } \\
\text { before treatment and half year after } \\
\text { treatment }\end{array}$ & $31.8210 / 0.0000$ & $17.4315 / 0.0000$ & $18.6309 / 0.0000$ & $18.0272 / 0.0000$ & $17.3521 / 0.0000$ & $5.7970 / 0.0000$ \\
\hline $\begin{array}{l}\text { Comparison of } \mathrm{T} \text { value/p value } \\
\text { before treatment and one year after } \\
\text { treatment }\end{array}$ & $35.7762 / 0.0000$ & $19.0755 / 0.0000$ & $19.8023 / 0.0000$ & $18.4918 / 0.0000$ & $17.6386 / 0.0000$ & $5.7970 / 0.0000$ \\
\hline $\begin{array}{l}\text { Comparison of } \mathrm{T} \text { value/p value on } \\
\text { the day after treatment and half year } \\
\text { after treatment }\end{array}$ & $2.2737 / 0.0120$ & $1.3098 / 0.0959$ & $2.6930 / 0.0038$ & $3.3604 / 0.0005$ & $3.7588 / 0.0001$ & $0.7652 / 0.2225$ \\
\hline $\begin{array}{l}\text { Comparison of } \mathrm{T} \text { value/p value on } \\
\text { the day after treatment and one year } \\
\text { after treatment }\end{array}$ & $3.6338 / 0.0002$ & $2.4633 / 0.0073$ & $3.5551 / 0.0002$ & $3.9205 / 0.0001$ & $4.1483 / 0.0000$ & $0.7652 / 0.2225$ \\
\hline $\begin{array}{c}\text { Comparison of } \mathrm{T} \text { value/p value for } \\
\text { half a year after treatment and one } \\
\text { year after treatment }\end{array}$ & $1.5974 / 0.0559$ & $1.1950 / 0.1168$ & $0.8676 / 0.1933$ & $0.5992 / 0.2748$ & $0.4525 / 0.3257$ & $0.0000 / 0.5000$ \\
\hline
\end{tabular}

\subsection{Comparison of Postpartum Pelvic Floor Function in Control Group before and after Treatment}

In the control group, the myoelectric potential value of pelvic floor function, muscle type I muscle strength, muscle type II muscle strength, muscle type I fatigue, muscle type II fatigue, POP-Q test before and after treatment, before and half a year after treatment, before and one year after treatment, the differences were statistically significant $(\mathrm{p}<0.001)$. There were significant differences in EMG potential, muscle class I fatigue and muscle type II fatigue between the two groups on the same day and half a year after treatment $(\mathrm{p}<0.05)$. There was no significant difference between the two indexes of muscle type I muscle strength and muscle type II muscle strength on the same day and half a year after treatment $(p>0.05)$. There was no significant difference in EMG potential, muscle I muscle strength, muscle class II muscle strength, muscle type I fatigue, muscle type II fatigue on the day after treatment and the year after treatment ( $p>0.05)$. There was no significant difference in muscle strength I, muscle type II muscle strength, muscle class I fatigue and muscle type II fatigue between half a year after treatment and one year after treatment $(\mathrm{p}>0.05)$. There was significant difference in EMG between half a year after treatment and one year after treatment $(\mathrm{p}<0.05)$. There was no significant difference in POP-Q detection between the day after treatment and half a year after treatment, the day after treatment and one year after treatment, and the difference between half a year after treatment and one year after treatment $(\mathrm{p}>0.05)$. See Table 8 below for details. 
Table 8. Comparison of postpartum pelvic floor function in control group before and after treatment.

\begin{tabular}{|c|c|c|c|c|c|c|}
\hline Project & EMG Value & $\begin{array}{l}\text { Muscle Type I } \\
\text { Muscle Strength }\end{array}$ & $\begin{array}{l}\text { Muscle Type II } \\
\text { Muscle Strength }\end{array}$ & $\begin{array}{l}\text { Muscle Type I } \\
\text { Fatigue }\end{array}$ & $\begin{array}{c}\text { Muscle Type II } \\
\text { Fatigue }\end{array}$ & POP-Q Test \\
\hline Before Treatment & $5.73 \pm 1.89$ & $1.61 \pm 0.62$ & $1.61 \pm 0.60$ & $-2.66 \pm 0.91$ & $-2.4 \pm 0.99$ & $-4.58 \pm 0.79$ \\
\hline On the Day of Treatment & $14.60 \pm 3.65$ & $2.76 \pm 0.81$ & $2.89 \pm 0.76$ & $-1.28 \pm 0.85$ & $-1.03 \pm 0.85$ & $-5.00 \pm 0.36$ \\
\hline Half a Year After Treatment & $15.41 \pm 3.24$ & $2.9 \pm 0.69$ & $3.03 \pm 0.76$ & $-1.05 \pm 0.76$ & $-0.79 \pm 0.74$ & $-5.01 \pm 0.35$ \\
\hline One Year After Treatment & $14.50 \pm 2.99$ & $2.77 \pm 0.58$ & $2.88 \pm 0.59$ & $-1.20 \pm 0.74$ & $-0.89 \pm 0.75$ & $-5.01 \pm 0.35$ \\
\hline $\begin{array}{l}\text { Comparison of } \mathrm{T} \text { value/p value } \\
\text { before treatment and on the day } \\
\text { of treatment }\end{array}$ & $21.5799 / 0.0000$ & $11.4085 / 0.0000$ & $13.2191 / 0.0000$ & $11.0823 / 0.0000$ & $10.4994 / 0.0000$ & $4.8378 / 0.0000$ \\
\hline $\begin{array}{c}\text { Comparison of } \mathrm{T} \text { value/p value } \\
\text { before treatment and half year } \\
\text { after treatment }\end{array}$ & $25.8067 / 0.0000$ & $14.1078 / 0.0000$ & $14.6649 / 0.0000$ & $13.5794 / 0.0000$ & $13.0259 / 0.0000$ & $4.9765 / 0.0000$ \\
\hline $\begin{array}{l}\text { Comparison of } \mathrm{T} \text { value/p value } \\
\text { before treatment and one year } \\
\text { after treatment }\end{array}$ & $24.7932 / 0.0000$ & $13.9004 / 0.0000$ & $15.0923 / 0.0000$ & $12.4478 / 0.0000$ & $12.1577 / 0.0000$ & $4.9765 / 0.0000$ \\
\hline $\begin{array}{l}\text { Comparison of } \mathrm{T} \text { value/p value } \\
\text { on the day after treatment and } \\
\text { half year after treatment }\end{array}$ & $1.6596 / 0.0493$ & $1.3157 / 0.0949$ & $1.3026 / 0.0971$ & $2.0172 / 0.0225$ & $2.1296 / 0.0172$ & $0.1992 / 0.4212$ \\
\hline $\begin{array}{l}\text { Comparison of } \mathrm{T} \text { value/p value } \\
\text { on the day after treatment and } \\
\text { one year after treatment }\end{array}$ & $0.2119 / 0.4162$ & $0.1004 / 0.4601$ & $0.1039 / 0.4587$ & $0.7099 / 0.2393$ & $1.2350 / 0.1091$ & $0.1992 / 0.4212$ \\
\hline $\begin{array}{l}\text { Comparison of } \mathrm{T} \text { value/p value } \\
\text { for half a year after treatment } \\
\text { and one year after treatment }\end{array}$ & $2.0640 / 0.0202$ & $1.4422 / 0.0754$ & $1.5590 / 0.0603$ & $1.4141 / 0.0795$ & $0.9491 / 0.1719$ & $0.0000 / 0.5000$ \\
\hline
\end{tabular}

\subsection{Whether There Were Urinary Incontinence before and after Treatment in Both Groups}

In the treatment group, there were 15 cases of grade I urinary incontinence and 4 cases of grade II urinary incontinence before treatment; At the day of treatment, there were 6 cases of grade I urinary incontinence and 0 cases of grade II urinary incontinence; Six months after treatment, there were 4 cases of grade I urinary incontinence and 0 cases of grade II urinary incontinence; One year after treatment, there were 4 cases of grade I urinary incontinence and 0 cases of grade II urinary incontinence. In the control group, there were 14 cases of grade I urinary incontinence and 4 cases of grade II urinary incontinence before treatment; At the day of treatment, there were 11 cases of grade I urinary incontinence and 0 cases of grade II urinary incontinence; Six months after treatment, there were 11 cases of grade I urinary incontinence and 0 cases of grade II urinary incontinence; One year after treatment, there were 11 cases of grade I urinary incontinence and 0 cases of grade II urinary incontinence. There was no significant difference in urinary incontinence between the two groups before and after the day of treatment ( $p>0.05)$; there was significant difference between half a year and one year after treatment $(p<0.05)$. See Table 9 below for details. 


\subsection{Comparison of the Quality of Sexual Life before and after Treatment in Both Groups}

In the treatment group, 24 cases were not satisfied with their sexual life before treatment, and thought that the sexual life was dry and astringent; 76 cases were afraid of perineal pain after childbirth and did not dare to have sex life; 89 cases were satisfied with sexual life and 11 cases were not satisfied with sexual life at the end of treatment; Six months after treatment, 96 cases were satisfied with sexual life and 4 cases were not satisfied with sexual life; One year after treatment, 97 cases were satisfied with sexual life and 3 cases were not satisfied with sexual life. In the control group, 26 cases were not satisfied with their sexual life before treatment, and their sexual life was dry and astringent; 74 cases were afraid of perineal pain after childbirth and did not dare to have sex life; 74 cases were satisfied with sexual life and 26 cases were not satisfied with sexual life at the end of treatment; Half a year after treatment, 76 cases were satisfied with sexual life and 24 cases were not satisfied with sexual life; One year after treatment, 79 cases were satisfied with sexual life and 21 cases were not satisfied with sexual life. There were no statistically significant differences between the two groups in terms of dissatisfaction with sexual life and lack of sexual life before treatment, $(\mathrm{p}>0.05)$; After treatment, half a year after treatment and one year after treatment, the difference in satisfaction with sexual life was statistically significant $(\mathrm{p}<0.05)$. The specific results are shown in Table 10 below.

Table 9. Comparison of urinary incontinence before and after treatment in both groups (Cases).

\begin{tabular}{|c|c|c|c|c|c|c|c|c|}
\hline \multirow[b]{2}{*}{ Group } & \multicolumn{2}{|c|}{ Before Treatment } & \multicolumn{2}{|c|}{ On the Day of Treatment } & \multicolumn{2}{|c|}{ Half Year after Treatment } & \multicolumn{2}{|c|}{ One Year after Treatment } \\
\hline & $\begin{array}{c}\text { Grade I } \\
\text { Urinary } \\
\text { Incontinence }\end{array}$ & $\begin{array}{c}\text { Grade II } \\
\text { urinary } \\
\text { incontinence }\end{array}$ & $\begin{array}{c}\text { Grade I } \\
\text { Urinary } \\
\text { Incontinence }\end{array}$ & $\begin{array}{c}\text { Grade II } \\
\text { urinary } \\
\text { incontinence }\end{array}$ & $\begin{array}{c}\text { Grade I } \\
\text { Urinary } \\
\text { Incontinence }\end{array}$ & $\begin{array}{c}\text { Grade II } \\
\text { urinary } \\
\text { incontinence }\end{array}$ & $\begin{array}{c}\text { Grade I } \\
\text { Urinary } \\
\text { Incontinence }\end{array}$ & $\begin{array}{c}\text { Grade II } \\
\text { urinary } \\
\text { incontinence }\end{array}$ \\
\hline $\begin{array}{l}\text { Treatment } \\
\text { Group }\end{array}$ & 15 & 4 & 6 & 0 & 3 & 0 & 3 & 0 \\
\hline $\begin{array}{l}\text { Control } \\
\text { Group }\end{array}$ & 14 & 4 & 11 & 0 & 11 & 0 & 11 & 0 \\
\hline$\chi^{2}$ Value & \multicolumn{2}{|c|}{0.0332} & \multicolumn{2}{|c|}{1.6072} & \multicolumn{2}{|c|}{4.9155} & \multicolumn{2}{|c|}{4.9155} \\
\hline $\mathrm{p}$ Value & \multicolumn{2}{|c|}{0.8555} & \multicolumn{2}{|c|}{0.2049} & \multicolumn{2}{|c|}{0.0266} & \multicolumn{2}{|c|}{0.0266} \\
\hline
\end{tabular}

Table 10. Comparison of sexual life satisfaction between the two groups before and after treatment.

\begin{tabular}{|c|c|c|c|c|c|c|c|c|}
\hline \multirow{2}{*}{ Group } & \multicolumn{2}{|c|}{ Before Treatment } & \multicolumn{2}{|c|}{$\begin{array}{l}\text { At the End of } \\
\text { Treatment }\end{array}$} & \multicolumn{2}{|c|}{ Half Year after Treatment } & \multicolumn{2}{|c|}{ One Year after Treatment } \\
\hline & Not Satisfied & Afraid to have sex & Satisfaction & Not Satisfied & Satisfaction & Not Satisfied & Satisfaction & Not Satisfied \\
\hline $\begin{array}{l}\text { Treatment } \\
\text { Group }\end{array}$ & 24 & 76 & 89 & 11 & 96 & 4 & 97 & 3 \\
\hline $\begin{array}{l}\text { Control } \\
\text { Group }\end{array}$ & 26 & 74 & 74 & 26 & 76 & 24 & 79 & 21 \\
\hline$\chi^{2}$ Value & \multicolumn{2}{|r|}{0.1067} & \multicolumn{2}{|c|}{7.4614} & \multicolumn{2}{|c|}{16.6113} & \multicolumn{2}{|c|}{15.3409} \\
\hline $\mathrm{p}$ Value & \multicolumn{2}{|r|}{0.744} & \multicolumn{2}{|c|}{0.0063} & \multicolumn{2}{|c|}{0.0000} & \multicolumn{2}{|c|}{0.0001} \\
\hline
\end{tabular}




\section{Discussion}

Electrical stimulation is a passive pelvic floor physical rehabilitation method widely used in pelvic organ shedding and urinary incontinence; however, the mechanism of electrical stimulation has not been perfected [16] [17] [18]. The treatment of urinary incontinence mainly plays the role of the following aspects: a pair of external urinary sphincter contractions are regularly stimulated, and the urinary sphincter contraction ability is effectively improved through the neural circuit, and the urine control ability is enhanced; And then the muscles and nerves are fully stimulated to form impulses, which make the sympathetic pathways excited, inhibit the parasympathetic channels, and control bladder contraction. Each parturient has different physique, postpartum pelvic floor function injury is different, pelvic floor function recovery is not the same, such as muscle contraction ability, learning ability is different, some parturients have better contractile ability to class I fibers, some parturients have better contractile ability to class II fibers, and a small part even lose the ability to contract pelvic floor muscles [19] [20] [21] [22] [23]. Therefore, it is difficult to achieve a unified treatment standard and fixed training mode for postpartum pelvic floor muscle function rehabilitation. It is necessary to follow the principle of individualized rehabilitation treatment, adjust the individual characteristics and rehabilitation effect of parturients in time, and formulate individualized treatment plans and training models [24] [25] [26]. In the course of the study, the research team tried to select maternal patients with similar symptoms and similar basic conditions as the research object; there was no statistical difference between the physical signs and treatment indicators before treatment to ensure that the treatment was comparable. Vaginal dumbbells are also called shrinking dumbbells; They are similar in height to the dumbbells used in daily exercise equipment; They are composed of two elliptical balls; The slender connecting band in the middle is very strong and tough; This delicate design plays a good role in vaginal muscle contraction; The vibration toughness and strength in the process of use are strengthened [27]-[33]. Because the vagina of pregnant woman is a very elastic organ, when the muscle dilates, it can accommodate the passage of a newborn, but after giving birth, the womb is drooping, the vagina is relaxed, the elasticity is weakened, the secretion is increased, the guide dumbbell must be used for training, so that the vaginal muscle elasticity of the parturient can be restored, the muscle contractility and sucking power can be improved, the muscle contraction can be guided freely in the course of sexual life, and the quality of sexual life must be guaranteed [34] [35] [36] [37]. At the same time, it is consistent of related reports to control the urinary incontinence of parturients and reduce the probability of postpartum urinary incontinence [38] [39] [40]. When the pelvic floor muscles are passively contracted, the functional rehabilitation device effectively stimulates the pelvic floor muscles by its own gravity, so that the pelvic floor undergoes independent contraction, thereby enhancing the pelvic floor function and muscle tension, promoting the early recovery of partu- 
rients and preventing the occurrence of pelvic floor dysfunction diseases.

The results of this study showed that the EMG values, Class I muscle strength, Class II muscle strength, muscle Class I fatigue, Class II fatigue and POP-Q tests were compared between the two groups; There was no significant difference before treatment, $p>0.05$, which indicated that the postpartum pelvic floor function of the two groups before treatment was basically the same, and the difference after treatment was comparable.

On the day after treatment, the sixth month and the year, the difference of type I muscle strength, type II muscle strength and muscle type I fatigue of pelvic floor muscles was statistically significant, $\mathrm{p}<0.05$, which indicated that the recovery of pelvic floor function muscle type I muscle strength, class II muscle strength and muscle type I fatigue in the treatment group was superior to that in the control group; However, there was no significant difference in muscle type II fatigue treatment on the end of treatment $(\mathrm{p}>0.05)$.

Six months and one year after treatment, the difference was statistically significant $(\mathrm{p}<0.05)$, indicating that the muscle type II fatigue treatment group was less fatigued than the control group in the six months and one year after treatment. There was no significant difference in the POP-Q detection treatment on the day after the treatment, six months and one year after treatment, $p>0.05$, indicating that there was no difference in POP-Q results before and after treatment between the two groups. It can be seen from the above that electrical stimulation biofeedback therapy combined with vaginal dumbbell has good curative effect on the rehabilitation of postpartum pelvic floor dysfunction patients, and it is worthy of popularization and application by medical workers.

The results also showed that there were significant differences in EMG, Class I muscle strength, Class II muscle strength, muscle Class I fatigue, Class II fatigue and POP-Q between the treatment group and the control group before and after treatment, which indicated that the therapeutic effect was significant. The results also suggested that there was no significant difference in urinary incontinence between the two groups before treatment and on the day of treatment $(p>0.05)$; there was significant difference between half a year and one year after treatment $(p<0.05)$. It also showed that urinary incontinence in the treatment group is effectively controlled after treatment, which was obviously improved compared with the control group; Before treatment, the two groups were not satisfied with the sexual life, and the number of cases who were afraid to have sex was not statistically significant, $\mathrm{p}>0.05$; After the day of treatment, half a year after treatment, and one year after treatment, the satisfaction of sexual life was statistically significant, $\mathrm{p}<0.05$, indicating that the treatment group achieved better satisfaction in terms of sexual life after treatment; The effect was significantly better than that of the control group. From the analysis of statistical data, the changes of various indexes in the treatment group before and after treatment were more significant than those in the control group, which indirectly indicated that the curative effect of the treatment group was more obvious than that of the control 
group, suggesting that the effect of electrical stimulation biofeedback therapy combined with vaginal dumbbell on the rehabilitation of patients with postpartum pelvic floor dysfunction was obvious, and it is worth popularizing and applying.

\section{Conclusion}

Electrical stimulation is a passive physical rehabilitation method of pelvic floor. Functional rehabilitation device (vaginal dumbbell) plays an important role in passive contraction of pelvic floor muscle. Electrical stimulation biofeedback therapy combined with vaginal dumbbell has a good effect on the rehabilitation of patients with postpartum pelvic floor dysfunction. The results of this study show that the use of electrical stimulation biofeedback therapy combined with vaginal dumbbells for the treatment of postpartum pelvic floor dysfunction patients is more effective than traditional simple electrical stimulation biofeedback therapy, and has important clinical significance for the rehabilitation of maternal pelvic floor function. The results obtained in this study have brought good news to patients with clinical treatment of pelvic floor dysfunction, and have played an important role in social and economic development, with good social and economic benefits.

\section{Limitations of Research}

The main observations in this study are limited and have certain limitations. The number of research cases can be expanded to obtain more powerful evidence. In addition, the follow-up time of this study is relatively long, and the patient's compliance with follow-up has a certain complexity, which has a certain impact on the results.

\section{Fund Project}

Guangxi Baise scientific research and technology development plan project (NO.: encyclopedia 20171124).

\section{Acknowledgements}

This project was established, received the strong support of the hospital functional department and the help of colleagues, in the implementation process, it has also received the strong help and support of the colleagues and patients as well as the family members of the patients. Here, we would like to express our heartfelt thanks for their support and help! Wish them good health, smooth work and all the best!

\section{Conflicts of Interest}

The authors declare no conflicts of interest regarding the publication of this paper. 


\section{References}

[1] Xu, M. (2019) Pelvic Floor Rehabilitation Combined with Bioelectric Stimulation to Treat Pelvic Floor Dysfunction in Different Delivery Methods. Chinese Journal of Family Planning, 27, 453-456.

[2] Li, J.Y., Sun, W.M., Zheng, Q.M., et al. (2017) The Role of Pelvic Floor Muscle Function Training Combined with Bioelectric Stimulation in Postpartum Pelvic Floor Muscle Function Rehabilitation. Chinese Maternal and Child Health Care, 32, 4695-4697.

[3] Liu, K.H. and Hao, J.Q. (2017) Observation on the Efficacy of Biofeedback Electrical Stimulation Combined with Pelvic Floor Muscle Training in the Treatment of Female Pelvic Floor Organ Prolapse. Chinese Journal of Physics and Rehabilitation, 39, 694-697.

[4] Zhang, H., Tang, W. and Zhao, Y. (2019) Effect of Recent Postpartum Biofeedback Electrical Stimulation on Pelvic Floor Muscle Strength. Maternal and Child Health Care in China, 34, 1395-1397.

[5] Zhu, Y. (2018) Analysis of Influencing Factors of Short-Term Curative Effect of Postpartum Pelvic Floor Rehabilitation Therapy. Chinese Practical Medicine, 13, 9-11.

[6] Liu, C.H., Wen, F.Y. and Wang, S.Y. (2018) Clinical Study of Biofeedback Electric Stimulation Combined with Relaxation in the Treatment of Postnatal Pelvic Pain. Shandong Pharmaceutical, 58, 65-67.

[7] Hu, D.Q. (2017) Efficacy of Biofeedback Combined with Electrical Stimulation in the Treatment of Uterine Prolapsed. Maternal and Child Health Care in China, 32, 3353-3355.

[8] Liu, X., Shao, L., Liu, W., et al. (2018) To analyze the Effect of Biofeedback Electrical Stimulation Combined with Pelvic Floor Muscle Training on Postpartum Pelvic Floor Muscle Function Rehabilitation in Parturients. Maternal and Child Health Care in China, 33, 2432-2434.

[9] Liang, H.B., Ye, Z.Y., Chen, L.P., et al. (2018) Efficacy of EMG Biofeedback Combined with Neuromuscular Stimulation in the Treatment of Postpartum Stress Urinary Incontinence. Chinese Journal of Physics and Rehabilitation, 40, 365-367.

[10] Huang, L.X., Gu, Y.H., Fang, G.Y., et al. (2018) Analysis of Therapeutic Effect of Biofeedback Electrical Stimulation Combined with Psychological Intervention on Postpartum Female Sexual Dysfunction. Chinese Journal of Modern Medicine, 28, 73-77.

[11] Shi, Y. and Li, H.H. (2018) Clinical Efficacy of Pelvic Floor Muscle Training Combined with Biofeedback Electrical Stimulation in the Treatment of Pelvic Floor Dysfunction. Maternal and Child Health Care in China, 33, 4588-4590.

[12] Hu, Q.F., Zhu, Y.F., Hu, M.S., et al. (2018) Clinical Effect of Pelvic Floor Muscle Rehabilitation Training Combined with Biofeedback Electrical Stimulation in the Treatment of Pelvic Floor Dysfunction. Maternal and Child Health Care in China, 33, 4108-4110.

[13] Li, J.Y., Sun, W.M., Zheng, Q.M., et al. (2017) Effect of Biofeedback Electrical Stimulation Combined with Pelvic Floor Muscle Training in the Treatment of Postpartum Pelvic Floor Dysfunction. Maternal and Child Health Care in China, 32, 4945-4947.

[14] Jiang, W., Han, W., Liu, W.H., et al. (2017) Application Effect of Biofeedback Combined with Electrical Stimulation in Pelvic Floor Dysfunction. Maternal and Child 
Health Care in China, 32, 1780-1782.

[15] Dai, X., Zhou, J., Jiao, R.F., et al. (2018) Clinical Observation on Sexual Function of Female Pelvic Floor Dysfunction Rehabilitation Therapy. Chinese Contemporary Medicine, 25, 77-79.

[16] Jia, W.J., Wang, H. and Hu, C.L. (2018) Clinical Analysis of the Effect of Postpartum Pelvic Floor Rehabilitation. Health Care Literature Collection, No. 4, 13+15.

[17] Zhu, Y. (2017) Clinical Observation of Postpartum Pelvic Floor Rehabilitation in Women. Health Care Guide, No. 6, 227.

[18] Wang, Y.P. (2017) Preventive Value of Postpartum Pelvic Floor Muscle Rehabilitation in Patients with Pelvic Floor Dysfunction. Heilongjiang Medicine, 41, $1173-1175$.

[19] Zhou, Z.M., Xu, Q.Y. and Mo, J.Z. (2017) Effect of Electrical Stimulation Biofeedback Therapy Combined with Autonomous Consolidation Training in Postpartum Pelvic Floor Rehabilitation. Chinese Contemporary Medicine, 24, 71-75.

[20] Li, H.M. (2018) Effect of Biofeedback Combined with Electrical Stimulation Therapy on Pelvic Floor Muscle Strength in Patients with Postpartum Pelvic Dysfunction. Henan Medical Research, 27, 1489-1490.

[21] Xu, S.M. (2018) Clinical Observation of 120 Cases of Postpartum Pelvic Floor Rehabilitation. Electronic Journal of Clinical and Medical Literature, 5, 59.

[22] Li, L. (2018) Clinical Analysis and Evaluation of Postpartum Pelvic Floor Rehabilitation Treatment. Electronic Journal of Practical Gynecological Endocrine, 5, 1-2.

[23] Ding, F.C. (2017) Clinical Study of Electrical Stimulation Combined with Biofeedback in Postpartum Pelvic Floor Rehabilitation. Journal of Modern Electrophysiology, 24, 148-150+159.

[24] Jane, H.Q. (2019) The Effect of Biofeedback Combined with Electrical Stimulation on the Early Intervention and Treatment of the Hypodynamia of the Pelvic Floor of the Postpartum Pelvic Floor. Diet and Health Care, 6, 37-38.

[25] Tang, Q. (2018) A Comparative Study on the Treatment of Pelvic Floor Dysfunction in the First Parturient with Three Pelvic Floor Rehabilitation Therapy. Mother and Baby World, No. 4, 55.

[26] Guo, H.P. and Cai, L.H. (2018) Clinical Efficacy Analysis and Evaluation of 90 Cases of Postpartum Pelvic Floor Rehabilitation. Continuing Medical Education in China, 10, 82-83.

[27] Cui, H., Guo, H.F. and Zhang, X.H. (2018) Clinical Study of Low Frequency Electrical Stimulation Combined with Biofeedback and Vaginal Dumbbell in the Treatment of Postpartum Urinary Incontinence. Study on Maternal and Child Health in China, 29, 910-913.

[28] Wang, Z.J. (2019) Observation on the Curative Effect of Pelvic Floor Biofeedback and Electrical Stimulation Therapy, Vaginal Dumbbell Pelvic Floor Rehabilitation Training Combined with Systematic Nursing Intervention on Postpartum Pelvic Floor Muscle Strength Rehabilitation. Electronic Journal of Practical Gynecological Endocrine, 6, 119-120+125.

[29] Tang, Y.M. (2017) Evaluation of Biofeedback Combined with Electrical Stimulation Combined with Vaginal Dumbbell in the Treatment of SUI. Journal of Qiqihar Medical College, 38, 1805-1806.

[30] Ou, D.L., Qiu, J.C., Ye, Y.M., et al. (2017) Study of Biofeedback Electrical Stimulation Combined with Vaginal Dumbbell Training on Improving Pelvic Floor Muscle Tension after Delivery. Modern Chinese Medicine Application, 11, 189-191. 
[31] Hu, X.L., Yuan, X.Y. and Huang, J.J. (2017) Comparison of Biofeedback Combined with Electrical Stimulation and Vaginal Dumbbell Training in the Treatment of Pelvic Floor Dysfunction in Postpartum Women. Chinese Contemporary Medicine, 24, 94-96.

[32] Wang, X.Y., Wang, P.X. and Wang, X.M. (2017) Observation on the Effect of Vaginal Dumbbell Training Combined with Biofeedback Electrical Stimulation in the Treatment of Postpartum Female Pelvic Floor Dysfunction. Clinical Research, 25, $89+92$.

[33] Li, M.Y., Huang, X., Chen, H.Y., et al. (2019) Analysis of the Effect of Vaginal Dumbbell Pelvic Floor Rehabilitation Combined with Biofeedback Electrical Stimulation Training on Postpartum Pelvic Floor Muscle Strength and Fatigue. Medical Frontier, 9, 110-111.

[34] Mu, Y.C. (2018) Application Value of Pelvic Floor Rehabilitation in the Treatment of Pelvic Floor Dysfunction in Postpartum Women. Chinese and Foreign Women's Health Research, No. 9, 90+196.

[35] Gao, M.H. (2018) Analysis of the Effect of Different Pelvic Floor Rehabilitation on Pelvic Floor Dysfunction in Postpartum Women. Electronic Journal of practical Gynecological Endocrine, 5, 25+28.

[36] Li, Q. (2017) Study on the Effect of Pelvic Floor Rehabilitation after Total Hysterectomy. Medical Information, 30, 104-105.

[37] Yu, L.J. (2017) Observation of the Effect of Electric Stimulation Combined with Biofeedback Therapy on Maternal Pelvic Floor Muscles. Mother and Baby World, No. 5, 94 .

[38] Wang, X.Y. (2018) The Role of Biofeedback Electrical Stimulation in the Recovery of Pelvic Floor Muscle Function after Delivery. Chinese Contemporary Medicine, 25, 134-136.

[39] Liu, K.H., Hao, J.Q. and Shang, Y.M. (2018) Observation on the Curative Effect of Biofeedback Combined with Acupoint Electrical Stimulation on Stress Urinary Incontinence in Elderly Women. Chinese Journal of Rehabilitation Medicine, 33, 1457-1459.

[40] Wang, Z.H. and Ye, Q.H. (2018) Clinical Nursing of Optimizing Electrical Stimulation Biofeedback Regimen in the Treatment of Mixed Urinary Incontinence. Journal of Nursing and Further Education, 33, 1593-1595. 